\title{
Perfil microbiológico de polpas de frutas congeladas consumidas no nordeste brasileiro: Uma revisão sistemática
}

\author{
Microbiological profile of frozen fruit pulps consumed in Brazilian northeast: A systematic review \\ Perfil microbiológico de pulpas de fruta congeladas consumidas en el nordeste de brasil: Una \\ revisión sistemática
}

Recebido: 29/10/2021 | Revisado: 07/11/2021 | Aceito: 12/11/2021 | Publicado: 21/11/2021

Luis Felipe de Medeiros Gomes

ORCID: https://orcid.org/0000-0003-2159-156X Instituto Federal de Educação, Ciência e Tecnologia do Ceará, Brasil

E-mail: felipe.gomes08@aluno.ifce.edu.br

Mariana de Lima Teixeira

ORCID: https://orcid.org/0000-0001-5489-1070

Instituto Federal de Educação, Ciência e Tecnologia do Ceará, Brasil

E-mail: mariana.lima60@aluno.ifce.edu.br

Antonia Lucivania de Sousa Monte

ORCID: https://orcid.org/0000-0003-2504-5136

Instituto Federal de Educação, Ciência e Tecnologia do Ceará, Brasil E-mail: lucivania@ifce.edu.br

Luana Guabiraba Mendes

ORCID: https://orcid.org/0000-0001-8184-8588

Instituto Federal de Educação, Ciência e Tecnologia do Ceará, Brasil

E-mail: luanagmendes@gmail.com

\begin{abstract}
Resumo
O presente estudo teve por objetivo identificar o perfil microbiológico das polpas de frutas congeladas consumidas no nordeste brasileiro por meio de uma revisão bibliográfica do tipo sistemática de estudos publicados entre 2016 e agosto de 2021. As pesquisas foram realizadas em bases de dados selecionadas (Google Acadêmico, Periódicos CAPES e SciELO) utilizando-se os seguintes termos/descritores: polpa de fruta, perfil microbiológico, qualidade, nordeste, "fruit pulp", "microbiology profile", "quality" e "northeast" e suas combinações. Os resultados das buscas foram selecionados e analisados, compreendendo o objetivo do estudo, além de critérios de inclusão e exclusão. Foram encontrados 472 estudos, sendo o total de 20 artigos selecionados para coleta e síntese dos dados. Observou-se que as mais variadas polpas de fruta são consumidas pela região, com destaque para acerola, cajá, caju e maracujá. Os principais parâmetros microbiológicos avaliados foram: enumeração de coliformes totais e coliformes termotolerantes (80\%), contagem de bolores e leveduras $(70 \%)$ e pesquisa de Salmonella $(60 \%)$. As polpas de frutas congeladas consumidas no nordeste brasileiro apresentam problemas na padronização dos parâmetros microbiológicos estabelecidos pela legislação, resultando em produtos impróprios para o consumo. Diante do exposto, destaca-se a importância da aplicação correta das boas práticas de fabricação, bem como a capacitação do corpo técnico de controle de qualidade e fiscalização do processamento de polpas de fruta consumidas na região nordeste brasileiro.
\end{abstract}

Palavras-chave: Fruta; Microbiologia; Legislação.

\begin{abstract}
The present study aimed to identify the microbiological profile of frozen fruit pulps consumed in Brazilian northeastern through a systematic literature review from studies published between 2016 and August 2021. The research was carried out in selected databases (Google Scholar, CAPES, and SciELO) using the following terms/descriptors: fruit pulp, microbiological profile, quality, northeast, and "fruit pulp", "microbiology profile", "quality", "northeast" in the combinations. The search results were selected and analyzed, understanding the study's objective, besides the inclusion and exclusion criteria. A total of 472 studies were found, with 20 articles being selected for data collection and synthesis. It was observed that most varied fruit pulps are consumed by the region, especially acerola, cajá, cashew, and passion fruit. The main microbiological parameters evaluated were: enumeration of total coliforms and thermotolerant coliforms (80\%), mold and yeast count (70\%), and Salmonella research (60\%). The pulps of frozen fruits consumed in Brazilian northeastern present problems in the standardization of microbiological parameters established by the legislation, resulting in products improper for consumption. Given the stated, it stands out the importance of the correct application of good manufacturing practices and the training of the
\end{abstract}


technical quality control as the inspection staff of the processing fruit pulps consumed in the northeast region of Brazil.

Keywords: Fruit; Microbiology; Legislation.

\begin{abstract}
Resumen
El presente estudio tuvo como objetivo identificar el perfil microbiológico de las pulpas de fruta congeladas consumidas en el noreste de Brasil a través de una revisión bibliográfica del tipo sistemático de estudios publicados entre 2016 y agosto de 2021. Las explanadas de investigación se llevaron a cabo en bases de datos seleccionadas (Google Scholar, CAPES y SciELO Journals) utilizando los siguientes términos/descriptores: pulpa de fruta, perfil microbiológico, calidad, noreste y combinaciones. Se seleccionaron y analizaron los resultados de la búsqueda, comprendiendo el objetivo del estudio, además de los criterios de inclusión y exclusión. Se encontraron un total de 472 estudios, con un total de 20 artículos seleccionados para la recopilación y síntesis de datos. Se observó que la región consume las más variadas pulpas de frutas, especialmente acerola, cajá, anacardo y maracuyá. Los principales parámetros microbiológicos evaluados fueron: enumeración de coliformes totales y coliformes termotolerantes (80\%), recuento de moho y levadura (70\%) e investigación de Salmonella (60\%). Las pulpas de frutas congeladas consumidas en el nordeste de Brasil presentan problemas en la estandarización de los parámetros microbiológicos establecidos por la legislación, lo que resulta en productos no aptos para el consumo. En vista de lo anterior, destacamos la importancia de la correcta aplicación de las buenas prácticas de fabricación, así como la capacitación del personal técnico de control de calidad e inspección del procesamiento de pulpas de fruta consumidas en la región noreste de Brasil.
\end{abstract}

Palabras clave: Fruta; Microbiología; Legislación.

\title{
1. Introdução
}

Considerada um dos principais pilares do agronegócio, a fruticultura, arte de cultivar frutos in natura, apresenta-se como uma atividade de elevado potencial comercial no território brasileiro, caracterizado por condições edafo-climáticas que possibilitam a produção frutícola das mais variadas espécies durante todo o ano, constituindo uma importante ferramenta para a captação e distribuição de renda para os pequenos e médios produtores rurais (Zucoloto, Schmildt \& Coelho, 2015).

Segundo Vidal (2020), a fruticultura nordestina, responsável por 34,4\% da produção nacional em 2019, movimentou aproximadamente US\$ 669,7 milhões em fronteiras no comércio exterior, refletindo um aumento de 13\% quando comparado ao ano anterior. A valorização dos frutos como matéria-prima para as grandes indústrias, aliada à sua crescente inserção na base alimentar da população, vem ocasionando mudanças significativas em seus sistemas de produção e comercialização. As frutas possuem grande importância na nutrição humana, isso se dá por conta dos seus constituintes como fibras, vitaminas e sais minerais. No entanto, à facilidade de deterioração dos frutos e o armazenamento inadequado geram perdas na produção, dessa forma as polpas de frutas congeladas se tornam uma ótima alternativa de garantia para o aproveitamento das frutas, podendo assim serem preparadas no período de safra, e serem disponibilizadas em épocas de entressafra (Sousa et al., 2020).

As polpas mais importantes no mercado brasileiro são as obtidas do processamento de frutas tropicais como abacaxi, acerola, cupuaçu, goiaba, manga, maracujá, dentre outras, que resultam em produtos de elevada aceitação (Torres et al., 2020). O congelamento da polpa de fruta é uma forma de conservação que mantém as características da fruta. Esse método permite que o produtor utilize frutas que não correspondam aos padrões de comercialização da fruta in natura. As frutas na forma de polpa permitem o uso de frutas pouco conhecidas como as da região Nordeste (Matta, 2005).

De acordo com a Instrução Normativa ${ }^{\circ}$ 49, de 26 de setembro de 2018, polpa de fruta é definida como o produto não fermentado, não concentrado, obtido de frutos polposos, elaborado por meio de processos tecnológicos adequados a fim de assegurar sua apresentação e conservação até o momento do consumo. A polpa de fruta pode ser classificada como simples, que são aquelas polpas produzidas de uma única fruta polposa ou mista quando originada pela mistura de uma fruta polposa com outra fruta polposa ou fruta não polposa ou partes comestíveis de vegetais (Brasil, 2018).

Para garantir a segurança alimentar é necessário manter o controle de qualidade em todo o processo de elaboração e 
comercialização dos produtos. Para que o alimento seja seguro é preciso dar importância a padrões higiênico-sanitários em todo o processo de produção dos alimentos. O aumento no número de casos de doenças transmitidas por alimentos (DTAs), normalmente é relacionado a falhas ou inexistência de padrões operacionais (Silva et al., 2020). O termo Doenças Transmitidas por Alimentos (DTAs) corresponde a um grupo de síndromes causadas por micro-organismos patogênicos, parasitas, contaminantes físicos e químicos e que podem ser transmitidos aos seres humanos por meio de alimentos e águas. Entre os agentes etiológicos mais comuns estão Escherichia coli, Salmonella spp e Staphylococcus aureus.

Definição de critérios e padrões microbiológicos para alimentos colaboram para a manutenção da segurança sanitária dos alimentos, contribuindo assim, com a saúde pública. O padrão microbiológico é determinado como um critério que determina a aceitabilidade de um alimento diante da presença de perigos como micro-organismos (Perotto et al., 2021).

Diante do exposto, fica evidente a importância de realizar um estudo acerca da qualidade higiênico-sanitária das polpas de frutas congeladas, a fim de promover informações válidas capazes de contribuir com estratégias para o controle e prevenção das DTA's. Neste contexto, esta revisão sistemática tem por objetivo identificar o perfil microbiológico das polpas de frutas congeladas consumidas no nordeste brasileiro no período entre 2016 e agosto 2021.

\section{Metodologia}

\subsection{Caracterização do estudo}

O presente estudo refere-se a uma revisão de literatura, do tipo sistemática, com o objetivo de analisar os dados científicos sobre a qualidade microbiológica das polpas de frutas consumidas na região nordeste brasileiro.

Segundo Galvão e Pereira (2014) a revisão sistemática de literatura caracteriza-se como um estudo secundário, onde se utiliza de estudos primários como sua principal fonte de dados para identificar, coletar, analisar e sintetizar evidências significativas sobre um determinado tema.

\subsection{Estratégia de pesquisa}

A pesquisa de busca foi realizada durante os meses de Julho e Agosto de 2021, por meio das seguintes bases de dados on-line: Google Acadêmico, Periódico CAPES e Scientific Eletronic Library Online (SciELO).

As buscas foram realizadas utilizando-se os termos/descritores: polpa de fruta, perfil microbiológico, qualidade, nordeste, "fruit pulp", "microbiology profile", "quality" e "northeast". A fim de tornar a busca mais eficiente, utilizou-se o operador booleano "and" para correlacionar os termos/descritores da seguinte forma: "polpa de fruta and perfil microbiológico", "polpa de fruta and qualidade", "polpa de fruta and nordeste", bem como suas combinações na língua inglesa.

\subsection{Critérios de seleção}

Como primeiro critério de inclusão, realizou-se a busca por estudos originais que dissertassem sobre a qualidade microbiológica de polpas de frutas comercializadas na região nordeste, nas línguas portuguesas e inglesas, publicados no período de 2016 a Agosto de 2021. A definição do período tem-se por finalidade caracterizar a qualidade microbiológica das polpas de frutas congeladas comercializadas na região nordeste brasileiro no atual cenário.

Para segundo critério, foram utilizados filtros a fim de identificar estudos que respondessem ao objetivo do presente trabalho. O primeiro filtro buscou avaliar o título e palavras-chave, identificando estudos realizados na região nordeste brasileiro que tiveram como objeto de pesquisa polpas de frutas obtidas no comércio local, seguido do segundo filtro, correspondente a leitura do resumo e metodologia, onde foram selecionados artigos que realizaram análises microbiológicas. O 
terceiro filtro tratou-se da leitura dos resultados e discussões, com o intuito de avaliar a interpretação dos resultados obtidos. Por fim, realizou-se a leitura completa e incorporação dos estudos selecionados.

Foram excluídos do estudo artigos sem ligação direta com o objetivo da pesquisa em questão, monografias, dissertações, teses, capítulos de livro, artigos de revisão, bem como artigos duplicados nas bases de dados, sendo considerados uma única vez.

\subsection{Processo de seleção e coleta dos dados}

O total de 472 estudos foram encontrados mediante buscas nas bases de dados, onde foram analisados segundo o título e palavras-chave, resultando em 58 estudos, sendo estes examinados quanto ao resumo e metodologia, restando 35 estudos, que após leitura dos resultados e discussões e exclusão das não conformidades em relação a temática do estudo, resultaram na amostra do trabalho em questão. Ao final do processo de seleção, 20 estudos apresentaram-se em conformidade com os critérios estabelecidos, sendo incorporados à revisão sistemática, conforme descrito na Figura 1.

Figura 1. Fluxograma de seleção dos estudos.

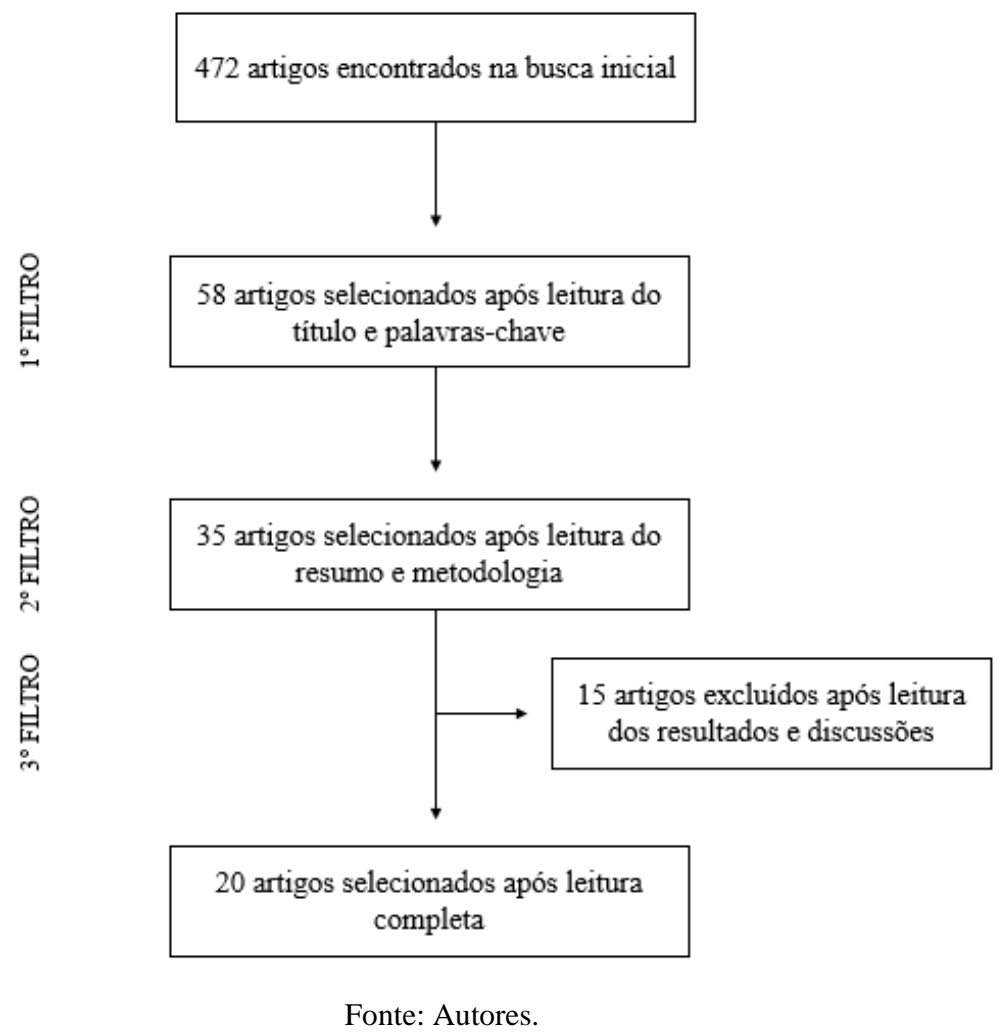

Os estudos selecionados foram analisados e apresentados no Quadro 1, expondo as principais informações acerca dos mesmos, destacando-se: autores e ano de publicação, polpas de frutas analisadas, parâmetros microbiológicos utilizados e principais resultados obtidos. Visando facilitar a discussão dos dados. 
Research, Society and Development, v. 10, n. 15, e105101522536, 2021

(CC BY 4.0) | ISSN 2525-3409 | DOI: http://dx.doi.org/10.33448/rsd-v10i15.22536

Quadro 1. Identificação e aspectos gerais dos artigos selecionados na revisão sistemática

\begin{tabular}{|c|c|c|c|c|}
\hline ID & Referência & Polpa de fruta & Parâmetro microbiológico & Principais descobertas \\
\hline $\mathbf{P 1}$ & Almeida et al. (2018) & Morango (8 amostras) & $\begin{array}{ll}\text { - } & \text { Bolores e leveduras } \\
\text { - } & \text { Coliformes totais } \\
\text { - } & \text { Salmonella spp }\end{array}$ & $\begin{array}{l}\text { As análises de bolores e leveduras das polpas congeladas mostraram que apenas as } \\
\text { polpas de } 3 \text { marcas atenderam o limite estabelecido. Os resultados da pesquisa de } \\
\text { E. coli nas oito amostras de polpas congeladas observa-se que as amostras de } 3 \\
\text { marcas apresentaram E. coli, não estando em conformidade com a legislação. Os } \\
\text { resultados da análise microbiológica para determinação de Salmonella spp. } \\
\text { apresentaram ausência em para todas as marcas. }\end{array}$ \\
\hline $\mathbf{P 2}$ & Almico et al. (2018) & Açaí (30 amostras) & $\begin{array}{ll}\text { - } & \text { Bolores e leveduras } \\
\text { - } & \text { Coliformes total e } \\
\text { - } & \text { Eschotolerantes } \\
& \text { Eschichia coli }\end{array}$ & $\begin{array}{l}\text { Apenas amostras de uma marca apresentou resultado positivo para coliformes } \\
\text { totais. Ambas as marcas de polpa de açaí, apresentaram análises negativas para } \\
\text { Coliformes termotolerantes e ausência de Salmonella sp em } 25 \mathrm{~g} \text { de amostra. No } \\
\text { que se refere, a enumeração de fungos, as três marcas avaliadas apresentaram } \\
\text { contaminação. }\end{array}$ \\
\hline $\mathbf{P 3}$ & Andrade et al. (2020) & Açaí (4 amostras) & $\begin{array}{ll}\text { - } & \text { Coliformes total e } \\
\text { - } & \text { Sermotolerantes } \\
\text { Salmonella spp }\end{array}$ & $\begin{array}{l}\text { Não foi observado crescimento de Salmonella sp nas amostras de polpa de açaí. } \\
\text { Não foi observado à presença de coliformes totais nas amostras analisadas e, } \\
\text { consequentemente, a ausência de coliformes termotolerantes. }\end{array}$ \\
\hline $\mathbf{P 4}$ & $\begin{array}{l}\text { Araújo, Alves \& Marques } \\
\text { (2018) }\end{array}$ & $\begin{array}{l}\text { Abacaxi, Cajá, Caju, Manga } \\
\text { e Maracujá (15 amostras) }\end{array}$ & - Bolores e leveduras & $\begin{array}{l}100 \% \text { das amostras analisadas apresentaram resultados dentro do padrão } \\
\text { estabelecido pela legislação vigente }\end{array}$ \\
\hline P5 & Feitosa et al. (2017) & $\begin{array}{l}\text { Acerola e Tamarindo }(6 \\
\text { amostras })\end{array}$ & $\begin{array}{ll}\text { - } & \text { Coliformes } \\
\text { - } & \text { termotolerantes } \\
\text { Salmonella spp }\end{array}$ & $\begin{array}{l}\text { Com base na contagem de Coliformes a } 45^{\circ} \mathrm{C} \text { e a presença de Salmonella spp., foi } \\
\text { verificado } 100 \% \text { de adequação das amostras. }\end{array}$ \\
\hline P6 & Ferreira et al. (2019) & Açaí (27 amostras) & $\begin{array}{l}\text { - } \quad \text { Coliformes totais e } \\
\text { termotolerantes } \\
\text { - } \quad \text { Escherichia coli }\end{array}$ & $\begin{array}{l}15 \text { amostras analisadas apresentam contagem para coliformes totais superior a } \\
1 \times 10^{2} \mathrm{NMP} \cdot \mathrm{g}^{-1} \text {. Ausência de contaminação por Salmonella } \mathrm{sp} \text {. }\end{array}$ \\
\hline P7 & Freitas et al. (2020) & $\begin{array}{l}\text { Acerola, Cajá, Caju e } \\
\text { Maracujá (12 amostras) }\end{array}$ & $\begin{array}{ll}\text { - } & \text { Bolores e leveduras } \\
\text { - } & \text { Coliformes totais e } \\
& \text { termotolerantes }\end{array}$ & $\begin{array}{l}\text { Foi observado que os resultados estavam de acordo com os padrões estabelecidos } \\
\text { pela legislação para coliformes termotolerantes. Para a contagem de bolores e } \\
\text { leveduras, verificou-se que as polpas de acerola (marca A, B e C); caju (marca A e }\end{array}$ \\
\hline
\end{tabular}


Research, Society and Development, v. 10, n. 15, e105101522536, 2021

(CC BY 4.0) | ISSN 2525-3409 | DOI: http://dx.doi.org/10.33448/rsd-v10i15.22536

\begin{tabular}{|c|c|c|c|c|}
\hline & & & - $\quad$ Salmonella spp & $\begin{array}{l}\text { B) e maracujá (marca A e B) apresentaram resultados acima do limite máximo } \\
\text { permitido pela legislação vigente. Para pesquisa de Salmonella sp. todas as } \\
\text { amostras analisadas apresentaram ausência. }\end{array}$ \\
\hline P8 & Guimarães et al. (2021) & $\begin{array}{l}\text { Acerola, Caju e Goiaba ( } 48 \\
\text { amostras) }\end{array}$ & 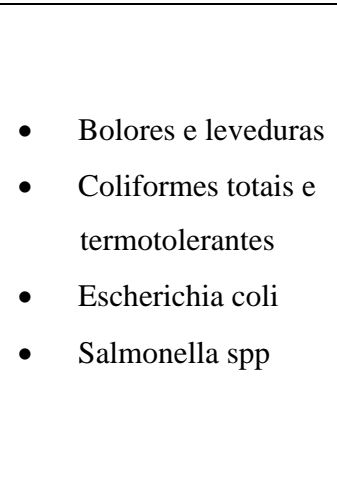 & $\begin{array}{l}58 \% \text { das amostras não estavam no limite estabelecido para bolores e leveduras pela } \\
\text { legislação, mas para E. coli e Salmonella sp. todas as amostras se encontraram } \\
\text { dentro dos padrões exigidos, pois em nenhuma das polpas foi detectado } \\
\text { crescimento desses microrganismos. Para coliformes termotolerantes, a polpa de } \\
\text { goiaba da marca e apresentou maior contaminação. Nas amostras do Lote } 2,54 \% \\
\text { das polpas de frutas não se enquadraram nos padrões estabelecidos para bolores e } \\
\text { leveduras, e em } 16,6 \% \text { foi detectada presença de E. coli. Contudo, não houve } \\
\text { crescimento de Salmonella sp., estando esse resultado de acordo com a legislação } \\
\text { vigente. }\end{array}$ \\
\hline P9 & Marinho et al. (2018) & Açaí (10 amostras) & $\begin{array}{l}\text { - } \\
\text { - } \\
\text { Coliformes totais } \\
\text { - } \\
\text { - } \\
\text { Eschermotolerantes } \\
\text { Outras bactérias }\end{array}$ & $\begin{array}{l}\text { Todas as amostras apresentaram-se fora dos padrões estabelecidos, indicando } \\
\text { contaminação por coliformes totais e termotolerantes, bolores e leveduras, } \\
\text { incluindo duas amostras positivas para E. coli. Ademais, não houve resultado } \\
\text { positivo para a presença de Salmonella sp. }\end{array}$ \\
\hline P10 & $\begin{array}{l}\text { Muniz, Reis \& Vieira } \\
\text { (2017) }\end{array}$ & $\begin{array}{l}\text { Acerola, Cajá e Goiaba }(27 \\
\text { amostras) }\end{array}$ & $\begin{array}{ll}\text { - } & \text { Coliformes totais } \\
\text { - } & \text { Escherichia coli }\end{array}$ & $\begin{array}{l}\text { Observa-se que as } 27 \text { amostras analisadas não apresentaram crescimento } \\
\text { coliformes totais e E. Coli, estando de acordo com os padrões estabelecidos. }\end{array}$ \\
\hline P11 & Neto et al. (2016) & $\begin{array}{l}\text { Caju, Maracujá, Morango e } \\
\text { Tamarindo ( } 20 \text { amostras) }\end{array}$ & $\begin{array}{ll}\text { - } & \text { Bolores e leveduras } \\
\text { - } & \text { teliformes totais e } \\
\text { - } & \text { Escherichia coli }\end{array}$ & $\begin{array}{l}\text { Os valores encontrados para bolores e leveduras nas amostras referentes a marca A } \\
\text { variam entre } 2,5 \times 10^{2} \text { e } 32 \times 10^{2} \mathrm{UFC} / \mathrm{g} \text {, com destaque para as amostras } \mathrm{n}^{\mathrm{o}} 3 \text { e } 5 \text {, dos } \\
\text { sabores Maracujá e Tamarindo, respectivamente, que apresentaram incontáveis } \\
\text { colônias. Todas as amostras apresentaram resultados negativos para presença de } \\
\text { coliformes totais e termotolerantes. }\end{array}$ \\
\hline P12 & Oliveira et al. (2020a) & Cajú (4 amostras) & $\begin{array}{l}\text { - } \quad \text { Bolores e leveduras } \\
\text { - Coliformes totais e } \\
\text { termotolerantes }\end{array}$ & $\begin{array}{l}\text { As marcas } 1 \text { e } 2 \text { apresentaram contaminação por fungos e leveduras acima dos } \\
\text { limites de segurança previstos na legislação em todos os lotes avaliados. As marcas } \\
3 \text { e } 4 \text { apresentaram contaminação acima dos limites de segurança exigido. Para } \\
\text { coliformes totais, as marcas } 1 \text { e } 2 \text { apresentaram valores elevados. Nenhuma das }\end{array}$ \\
\hline
\end{tabular}


Research, Society and Development, v. 10, n. 15, e105101522536, 2021

(CC BY 4.0) | ISSN 2525-3409 | DOI: http://dx.doi.org/10.33448/rsd-v10i15.22536

\begin{tabular}{|c|c|c|c|c|}
\hline & & & - $\quad$ Salmonela spp & $\begin{array}{l}\text { marcas apresentou contaminação por coliformes termotolerantes. Houve ausência } \\
\text { de Salmonella sp. em todas as marcas. }\end{array}$ \\
\hline P13 & Oliveira et al. (2020b) & Abacaxi (12 amostras) & $\begin{array}{ll}\text { - } & \text { Bolores e leveduras } \\
\text { - } & \text { Coliformes totais e } \\
& \text { termotolerantes } \\
\text { - } & \text { Salmonella spp }\end{array}$ & $\begin{array}{l}\text { Os resultados obtidos nas contagens de coliformes mostraram valores positivos } \\
\text { para } 7 \text { polpas, que foram analisados compreendendo diferentes lotes das marcas A } \\
\text { B e C. Apenas a marca D não obteve nenhum valor positivo para coliformes totais } \\
\text { entre os lotes. Um lote da marca B confirmou a presença de um coliforme } \\
\text { termotolerante. Todas as marcas analisadas mostraram valores coliformes abaixo } \\
\text { do limite máximo exigido por lei. A análise verificou a ausência de Salmonella sp } \\
\text { em em } 100 \% \text { das amostras. Os resultados obtidos na contagem de bolores } \\
\text { leveduras mostraram que apenas as amostras da marca D a estão dentro dos valores } \\
\text { determinados pela legislação. }\end{array}$ \\
\hline P14 & Santos \& Vieira (2020) & $\begin{array}{l}\text { Acerola, Cajá, Cajú, } \\
\text { Graviola, Manga, Mangaba, } \\
\text { Maracujá, Umbucaja e Uva } \\
\text { (16 amostras) }\end{array}$ & $\begin{array}{ll}\text { - } & \text { Bolores e leveduras } \\
\text { - } & \text { Coliformes totais e } \\
\text { - } & \text { termotolerantes } \\
\text { - } & \text { Ealmonella spp } \\
& \text { Escherichia coli }\end{array}$ & $\begin{array}{l}\text { Contagem total de Aeróbios Mesofilos em placas onde }(32,5 \%) \text { das amostras } \\
\text { apresentaram-se uma contagem elevada, acima do considerado seguro; para a } \\
\text { contagem de bolores e leveduras }(87,5 \%) \text { das amostras estavam acima do } \\
\text { determinado na legislação vigente; na contagem de Coliformes totais }(18,75 \%) \text { e } \\
\text { Coliformes termotolerantes }(37,5 \%) \text { estavam acima do estabelecido pela legislação } \\
\text { vigente, por fim o teste de Salmonella onde }(43,75 \%) \text { das amostras deram presença } \\
\text { desse tipo microrganismo. }\end{array}$ \\
\hline P15 & Santos et al. (2017) & $\begin{array}{l}\text { Acerola, Manga e Maracujá } \\
(9 \text { amostras })\end{array}$ & $\begin{array}{ll}\text { - } & \text { Aeróbios mesófilos } \\
\text { - } & \text { Bolores e leveduras } \\
\text { - } & \text { Coliformes totais } \\
\text { - } & \text { Escherichia coli } \\
\text { - } & \text { Salmonella spp }\end{array}$ & $\begin{array}{l}\text { De acordo com os resultados, foi observado que as polpas de frutas analisadas } \\
\text { encontravam-se dentro dos padrões estabelecidos pela legislação vigente com } \\
\text { relação a coliformes totais, E. coli, e Salmonella sp. Porém, houve crescimento } \\
\text { significativo de bolores e leveduras em duas das amostras avaliadas, sendo uma da } \\
\text { marca B e uma da marca C, apresentando resultados acima dos permitidos pela } \\
\text { legislação vigente. Já as bactérias mesófilas os resultados apresentaram uma } \\
\text { variação entre } 1 \times 10^{1} \text { e } 4,1 \times 10^{4} \mathrm{UFC} / \mathrm{g} \text {. }\end{array}$ \\
\hline P16 & Santos et al. (2020) & $\begin{array}{l}\text { Acerola, Cajá, Caju, } \\
\text { Goiaba, Graviola e } \\
\text { Maracujá (108 amostras) }\end{array}$ & $\begin{array}{ll}\text { - } & \text { Bolores e leverudas } \\
\text { - } & \text { Coliformes totais } \\
\text { - } & \text { Salmonella spp }\end{array}$ & $\begin{array}{l}\text { Em nenhuma das amostras de polpas de frutas foram constatadas contagens de } \\
\text { coliformes a } 35^{\circ} \mathrm{C} \text { e a } 45^{\circ} \mathrm{C} \text {, nem presença de Salmonella sp., sendo verificadas } \\
\text { baixas contagens de bolores e leveduras nas marcas testadas. }\end{array}$ \\
\hline
\end{tabular}




\begin{tabular}{|c|c|c|c|c|}
\hline P17 & $\begin{array}{l}\text { Santos, Neto \& Donzeli } \\
\text { (2016) }\end{array}$ & $\begin{array}{l}\text { Abacaxi, Cajá, Caju, } \\
\text { Manga, Maracujá, } \\
\text { Tamarindo e Uva ( } 28 \\
\text { amostras) }\end{array}$ & $\begin{array}{ll}\text { - } & \text { Bolores e leveduras } \\
\text { - } & \text { Coliformes totais e } \\
& \text { termotolerantes }\end{array}$ & $\begin{array}{l}\text { Polpas da marca A, } 14,29 \% \text { (todas do sabor maracujá), e polpas da marca } \mathrm{D} \\
14,29 \% \text { (todas do sabor abacaxi), apresentaram valores de bolores e leveduras } \\
\text { acima do padrão estabelecido pela Normativa } \mathrm{n}^{\circ} 1 \text { de } 7 \text { de janeiro de } 2000 \text {. Os } \\
\text { valores de bolores e leveduras encontrados nas polpas da marca A do sabor } \\
\text { maracujá e na marca D do sabor abacaxi apresentaram-se acima do padrão de } 5 \times \\
10^{3} \mathrm{UFC} / \mathrm{g} \text { estabelecido pela legislação. Foram encontrados coliformes totais na } \\
\text { marca C de quase todos os sabores analisados (exceto cajá), e houve presença de } \\
\text { coliformes termotolerantes a } 45^{\circ} \mathrm{C} \text { nas polpas dos sabores manga e caju, da marca } \\
\mathrm{C} \text {, com valores de } 9,1 \text { e } 1,44 \times 10^{1} \mathrm{NMP} / \mathrm{g} \text {. }\end{array}$ \\
\hline P18 & Silva et al. (2018) & (25 amostras) & $\begin{array}{ll}\text { - } & \text { Bolores e leveduras } \\
\text { - } & \text { Coliformes } \\
\text { termotolerantes } \\
\text { - Staphylococcus coagulase } \\
\text { positiva }\end{array}$ & $\begin{array}{l}\text { Observou-se que } 3 \text { amostras analisadas apresentaram valores para bolores } \\
\text { leveduras superiores ao estabelecido pela legislação. Para análise de coliformes } \\
\text { termotolerantes, } 100 \% \text { das amostras apresentaram a presença dos microrganismos } \\
\text { em baixas concentrações, estando de acordo com os padrões estabelecidos } \\
\text { Nenhuma das amostras apresentam resultados positivos para Staphylococcus. }\end{array}$ \\
\hline P19 & Souza et al. (2016) & $\begin{array}{l}\text { Abacaxi, Acerola, Cajá, } \\
\text { Goiaba, Graviola, Mamão, } \\
\text { Manga e Maracujá (40 } \\
\text { amostras) }\end{array}$ & $\begin{array}{ll}\text { - } & \text { Escherichia coli } \\
\text { - } & \text { Salmonella sp } \\
\text { - } & \text { Staphylococcus aureus }\end{array}$ & $\begin{array}{l}\text { Foi observado que } 82,50 \% \text { das polpas de frutas analisadas apresentavam } \\
\text { contaminação por microrganismos indesejáveis. Contaminação decorrente da } \\
\text { presença de Staphylococcus aureus e Salmonella sp., } 77,5 \% \text { e } 5 \% \\
\text { respectivamente. Nenhuma das amostras apresentaram resultados positivos para a } \\
\text { presença de Escherichia coli. }\end{array}$ \\
\hline $\mathbf{P 2 0}$ & Sousa et al. (2017) & $\begin{array}{l}\text { Cajá e Umbu-cajá (12 } \\
\text { amostras) }\end{array}$ & $\begin{array}{ll}\text { - } & \text { Bactérias mesófilas } \\
\text { - } & \text { Bolores e leveduras } \\
\text { - } & \text { Coliformes totais }\end{array}$ & $\begin{array}{l}\text { As polpas de cajá apresentaram contagens de bolores e leveduras que variaram em } \\
\text { concordância com a legislação vigente. Quanto às polpas de umbu-cajá, } \\
\text { contagem de bolores e leveduras das amostras } 1,3,4 \text { e } 6 \text {, não diferiu dos valores } \\
\text { encontrados nas de cajá. A amostra } 5 \text { de umbu-cajá apresentou contagem superior } \\
\text { ao determinado pela legislação brasileira, pela análise de coliformes totais, para a } \\
\text { análise dos coliformes termotolerantes, sendo que estes não foram detectados em } \\
\text { nenhuma das amostras. }\end{array}$ \\
\hline
\end{tabular}

Fonte: Autores. 


\section{Resultados e Discussão}

O total de 20 artigos foram selecionados e incorporados a análise do presente estudo, sendo destes $30 \%$ realizados no estado do Ceará, 20\% na Bahia, 15\% no Pernambuco, 10\% na Paraíba, 10\% no Piauí e 15\% somando os estados do Sergipe, Maranhão e Rio Grande do Norte, conforme gráfico apresentado na Figura 2.

Figura 2. Percentual de trabalhos realizados por estado.

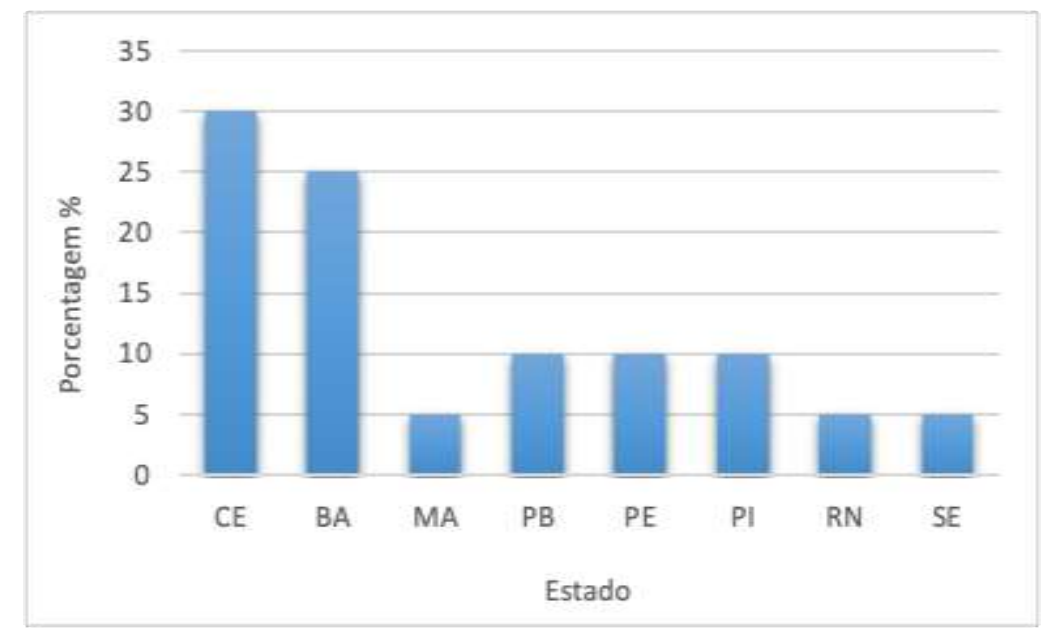

Fonte: Autores.

A fim de determinar a qualidade higiênico-sanitária das polpas de frutas em questão, observou-se que os principais parâmetros microbiológicos utilizados pelos artigos selecionados foram: enumeração de coliformes totais e termotolerantes, seguido da contagem de bolores e leveduras, e pesquisa de Salmonella sp. Ademais, outros parâmetros microbiológicos como, pesquisa de Escherichia coli, enumeração de Staphylococcus aureus e bactérias aeróbias mesófilas, também foram utilizados para investigação da qualidade, entretanto, em uma escala percentual menor.

\subsection{Coliformes totais}

Dentre os estudos analisados, 80\% (16 estudos) realizaram a enumeração de coliformes totais, grupo de microrganismos tidos como indicadores, devido sua valência de fornecer informações sobre a qualidade higiênico-sanitária do produto. Pertencente a família das Enterobacteriaceae, o grupo dos coliformes totais corresponde aos microrganismos que possuem a capacidade de fermentar a lactose e produzir gás a temperaturas de $35{ }^{\circ} \mathrm{C}$. Constituem esse grupo predominantemente bactérias entéricas originárias do trato gastrointestinal de humanos e animais de sangue quente, a exemplo da Escherichia coli, bem como bactérias não entéricas facilmente encontradas em ambientes como vegetais e solo, pertencentes aos gêneros Citrobacter, Enterobacter, Klebsiella, dentre outros (Silva et al., 2017).

Por meio da RDC $\mathrm{n}^{\circ} 12$, de 02 de Janeiro de 2001, principal legislação utilizada como padrão de avaliação da conformidade pelos estudos, a Agência Nacional de Vigilância Sanitária (ANVISA) estabelece padrões microbiológicos para alimentos, preconizando o limite máximo de $10^{2} \mathrm{UFC} / \mathrm{g}$ de coliformes totais para polpas de frutas concentradas ou não, com ou sem tratamento térmico, bem como refrigeradas ou congeladas (Brasil, 2001).

Em pesquisa realizada por Muniz, Reis \& Vieira (2017), identificada como P10, foi observada a ausência desses microrganismos em 100\% das amostras analisadas dos sabores acerola, cajá e goiaba, obtidas na região sudoeste da Bahia. Neto et al. (2020), identificação P11, obtiveram resultados semelhantes para polpas de caju, maracujá, morango e tamarindo 
comercializadas na cidade de Missão Velha - CE, registrando resultados negativos para coliformes totais em todas as polpas de frutas analisadas. Ambos os trabalhos encontram-se em conformidade com os padrões estabelecidos pela legislação vigente.

No estudo realizado no comércio local do município de Aracaju - SE, ao avaliarem a qualidade microbiológica de 30 amostras de açaí pasteurizadas de três diferentes marcas, Almico et al. (2018), identificação P2, relataram a presença de coliformes totais em amostras de apenas uma marca, apresentando $2,32 \times 10^{0} \mathrm{NMP} / \mathrm{g}$, contagem abaixo do limite máximo preconizado.

O não crescimento significativo de coliformes totais pode ser atribuído a um dos principais fatores intrínsecos das polpas de frutas, o seu pH. Segundo Sebastiany, Rego \& Vital (2009), os baixos valores de pHs encontrados nos frutos propiciam a proliferação de bolores e leveduras, visto que, as bactérias são mais exigentes, apresentando melhor desenvolvimento em faixas de $\mathrm{pH}$ mais próximas a neutralidade. Contudo, ainda é possível encontrar estudos onde foram verificados a presença de coliformes totais.

Marinho et al. (2018), identificado como P9, relataram a presença de coliformes totais em elevadas concentrações, 2,4 x $10^{3} \mathrm{NMP} / \mathrm{g}$, em $100 \%$ das amostras de polpa de açaí comercializadas no mercado público de São Luiz - MA como também Ferreira et al. (2019), identificação P6, verificaram contagens variando entre 2 x $10^{3}$ e 1 x $10^{4}$ UFC/g em 15 amostras de polpas de açaí produzidas no estado da Bahia. Ambos encontram-se fora dos padrões estabelecidos pela legislação, sendo seus objetos de estudo, classificados como alimentos impróprios para o consumo.

Do total de estudos que verificaram a presença de coliformes totais, 68,75\% (11 estudos) registraram a presença de coliformes totais em pelo menos uma das amostras analisadas. A presença desses microrganismos em elevadas concentrações pode indicar falhas na execução das Boas Práticas de Fabricação (BPF), além de evidências sobre potencial presença de patógenos e deterioração do alimento, refletindo condições higiênico-sanitárias precárias durante as etapas de elaboração, embalagem, armazenamento ou transporte (Franco \& Landgraf, 2008).

\subsection{Coliformes termotolerantes}

Caracterizado como subgrupo dos coliformes totais, os coliformes termotolerantes, comumente conhecidos como coliformes fecais, se diferenciam por sua capacidade de fermentar a lactose com produção de gás em temperaturas mais elevadas quando comparados aos coliformes totais, variando entre 44,5 e $45^{\circ} \mathrm{C}$. A princípio, constituíam este grupo somente enterobactérias oriundas do trato gastrointestinal, a exemplo da E. coli, entretanto, descobriu-se que cepas de gêneros distintos como a Klebsiella pneumoniae, Citrobacter freundii e Pantoea agglomerans possuem as mesmas características de fermentação. Dessa forma, o termo coliformes fecais gradativamente tem sido substituído pelo termo coliformes termotolerantes (Perotto et al., 2021; Silva et al., 2017)

O estudo de Santos, Neto \& Donzeli (2016), identificação P17, verificaram valores médios de 9,1 e 1,44 x 10¹ NMP/g para coliformes termotolerantes em polpas com os sabores manga e caju comercializadas nas cidades de Petrolina - PE e Juazeiro - BA, enquanto Freitas et al. (2020), identificação P7, registraram a presença de coliformes termotolerantes $(<3,0)$ em polpas de Acerola, Cajá, Caju e Maracujá comercializadas no município de Limoeiro do Norte - CE.

Ambos os estudos encontram-se de acordo com a RDC $\mathrm{n}^{\circ}$ 12, de 2 de Janeiro de 2001, que estabelece o limite máximo de $10^{2} / \mathrm{g}$ para coliformes termotolerantes. No entanto, os valores obtidos ultrapassam o limite preconizado pela IN $\mathrm{n}^{\circ}$ 49, de 26 de Setembro de 2018, que estabelece o valor máximo de 1/g para coliformes fecais em polpa de fruta (Brasil, 2001; Brasil, 2018). 
Em virtude, dos padrões distintos estabelecidos em cada legislação implica dificuldades na definição da qualidade da polpa de fruta, visto que, a depender da referência utilizada o produto pode ou não estar de acordo com os parâmetros requeridos.

Guimarães et al (2021), identificação P8, ao avaliarem polpas de acerola, caju e goiaba de diferentes marcas presentes no interior do Ceará, relataram valores entre $<3,0$ e 1 x $10^{2} \mathrm{NMP} / \mathrm{g}$, não ultrapassando o limite estabelecido pela Instrução Normativa n ${ }^{\circ}$ 01, de 07 de Janeiro de 2000 (Brasil, 2000). Entretanto, a variação dos valores encontrados indica não haver uma padronização nos processos de higienização e controle de qualidade por meio das indústrias da região.

Em um estudo desenvolvido por Andrade et al. (2020), identificado como P3, buscou avaliar a qualidade de polpas de açaí comercializadas em um estado do nordeste brasileiro, observou-se a ausência de coliformes termotolerantes em 100\% das amostras analisadas. Esse resultado evidencia a padronização das condições higiênico-sanitárias durante todas as etapas de elaboração, transporte e armazenamento das polpas de fruta, garantindo a conservação do produto até a chegada à mesa do consumidor.

Segundo Santos et al. (2020), a execução correta de técnicas de sanitização, processamento e armazenamento, aliadas à manipulação adequada da matéria-prima, são aspectos importantes capazes de inibir o desenvolvimento de enterobactérias, a exemplo dos coliformes fecais, promovendo a manutenção da qualidade microbiológica satisfatória das polpas de fruta.

Dentre o total das pesquisas que realizaram a análise de coliformes termotolerantes, 71,43\% (10 estudos), verificaram a presença dos microrganismos em pelo menos uma das amostras analisadas, dos quais $40 \%$ (4 estudos), apresentaram valores superiores aos estabelecidos pela legislação referência, sendo os objetos de estudos considerados como impróprios para o consumo.

\subsection{Bolores e leveduras}

Os bolores e leveduras são microrganismos indicadores de higiene. Os valores de referências estão na RDC 12/01 (Anvisa, 2001) e também na Normativa $N^{\circ} 60$ de 2019 (Brasil, 2019). A Instrução normativa ${ }^{\circ}$ 60, de 23 de dezembro de 2019 determina para bolores e leveduras o limite máximo de $10^{4}$. Os bolores podem se desenvolver com uma temperatura entre $25^{\circ} \mathrm{C}$ a $30^{\circ} \mathrm{C}$, mas algumas espécies se desenvolvem em temperaturas de refrigeração a $4^{\circ} \mathrm{C}$ a $5^{\circ} \mathrm{C}$. Estes microrganismos se desenvolvem com facilidade em alimentos de baixa atividade de água e baixo $\mathrm{pH}$, como por exemplo frutas frescas e vegetais (Perotto et al., 2021).

O estudo realizado por Araújo, Alves \& Marques (2018), identificado P4, as polpas congeladas de Abacaxi, Cajá, Caju, Manga e Maracujá (15 amostras), comercializadas no município de Salgueiro - PE, os autores encontraram valores de médios de 3,6 $\times 10^{2}$ e 1,0 x $10 \mathrm{UFC/g}$ para a análise de bolores e leveduras, quando compraram com os valores exigidos pela Instrução Normativa $n^{\circ}$ 01, de 07 de janeiro de 2000 que regulamenta e caracteriza a qualidade de polpas de frutas, os autores observaram que $100 \%$ das amostras estavam dentro dos valores permitidos para polpas de frutas.

Na pesquisa de Santos \& Vieira (2020), identificação P14, os autores analisaram 16 amostras de polpas de frutas artesanais de 9 sabores diferentes. Foram coletadas em 5 mercados públicos e feiras livres de João Pessoa - PB, para a contagem de bolores e leveduras nas polpas de Acerola, Cajá, Caju, Graviola, Manga, Mangaba, Maracujá, Umbu cajá e Uva, obtiveram como resultado valores como 9 × $10^{-4}$ e $8 \times 10^{-4} \mathrm{UFC} / \mathrm{g}$. Os resultados mostraram que 87,5\%, (14 das 16 amostras) das polpas analisadas estavam com valores acima do permitido pela legislação para esses microrganismos em polpas congeladas. De acordo com os autores a contagem elevada pode sugerir condições de manipulação e processamentos insatisfatórios. 
Santos et al. (2020), identificação P16, avaliaram polpas congeladas de Acerola, Cajá, Caju, Goiaba, Graviola e Maracujá (108 amostras) comercializadas em Recife - PE, ao realizarem a análise de bolores e leveduras obtiveram valores como $7 \times 10^{2}$ e $7,3 \times 10^{2}$. Os resultados mostraram que todas as polpas de frutas congeladas tiveram contagens desses microrganismos inferiores aos valores preconizados pela legislação. Segundo os autores encontrar baixas contagens de bolores e leveduras é considerado normal.

Em sua pesquisa, Silva et al. (2018), identificado como P18, verificaram a qualidade microbiológica de polpas de frutas comercializadas em Santo Antônio de Jesus (Bahia). Os resultados obtidos para as análises de bolores e leveduras foram valores de $<10$ até $2,5 \times 10^{5}$. De acordo com os autores as polpas não estavam com os valores acima do recomendado pela legislação destes alimentos.

A presença destes fungos em alimentos pode indicar falhas no uso das Boas Práticas de Fabricação (BPF), e também a presença de micotoxinas, que são produtos metabólicos secundários produzidos pelos bolores. Quando essas micotoxinas são ingeridas, dependendo da concentração e do tempo de exposição, elas podem provocar manifestações toxicológicas agudas e crônicas que são prejudiciais aos seres humanos. A análise de Perigos e Pontos Críticos de Controle, e também as Boas Práticas Agrícolas e as Boas Práticas de Fabricação nas etapas de pré e pós-colheita asseguram um papel fundamental na prevenção e manejo das micotoxinas (Perotto et al., 2021).

\subsection{Salmonella spp.}

A Salmonella é um gênero de bactéria da família Enterobacteriaceae, são bactérias gram-negativas, anaeróbias facultativas. A temperatura ótima de multiplicação é $38^{\circ} \mathrm{C}$ e a mínima de $5^{\circ} \mathrm{C}$, não formam endósporos, são termos sensíveis e podem ser destruídas a $60^{\circ} \mathrm{C}$, em 15 a 20 minutos. Essa bactéria pode se multiplicar na superfície de brotos de alface, tomates, outras frutas e vegetais crus. Por isso é extremamente importante fazer o uso de práticas higiênicas durante a manipulação desses produtos para reduzir sua contaminação (Forsythe, 2013).

No Brasil a Instrução Normativa no 60/2019 determina a lista de padrões microbiológicos para alimentos. Segundo a IN 60/2019 os resultados para Salmonella spp. devem ser expressos como "presença" ou "ausência" em 25 g ou 25 ml na amostra analisada, isso é, não existe um limite de tolerância como ocorre para outros patógenos (Brasil, 2019).

Em uma pesquisa realizada por Feitosa et al. (2017), identificado P5 ao analisar polpas congeladas de Acerola e Tamarindo (6 amostras) comercializadas em supermercados de Picos - PI, na pesquisa de Salmonella spp., todas as amostras tiveram ausência desse microrganismo foi verificado $100 \%$ de adequação das amostras. Oliveira et al. (2020b), identificação P13, em sua pesquisa os autores verificaram a qualidade microbiológica de polpas congeladas de abacaxi, comercializadas em Limoeiro do Norte - CE. Os resultados obtidos mostraram ausência de Salmonella em todas as amostras, dessa forma concluise que aplicaram as práticas de higiênicas durante a manipulação foram de forma correta. Oliveira et al. (2020a), identificado P12, analisou polpas de caju de 4 marcas, sendo duas pasteurizadas e duas não pasteurizadas, para análise de Salmonella os autores também verificaram ausência em todas as marcas, o que está de acordo com a Resolução RDC nº 12 , de 2 de janeiro de 2001 (Brasil, 2001). Foi possível observar que mesmo com a não utilização das técnicas de pasteurização, a aplicação correta das boas práticas de fabricação constituem uma ferramenta eficaz para a elaboração de um produto com condições higiênicosanitárias satisfatórias, promovendo a ausência do microrganismo Salmonella.

Almeida et al. (2018), identificação P1, em seu estudo realizaram a análise microbiológica de Salmonella. A análise foi feita em 8 marcas de polpas de frutas de morango comercializadas em Campina Grande - PB. A partir dos resultados da análise, os autores verificaram ausência de Salmonella em todas as amostras avaliadas. De acordo com os autores a presença deste microrganismo pode causar doenças e por isso se torna imprópria para o consumo. 


\subsection{Outros microrganismos}

Os aeróbios mesófilos estão largamente distribuídos na natureza e podem ser encontrados em animais de sangue quente, em ambientes terrestres e aquáticos. A temperatura ótima para seu crescimento é em torno de $32{ }^{\circ} \mathrm{C}$. A contagem destes microrganismos informa as condições higiênico-sanitárias em que os alimentos foram beneficiados. Altas contagens podem indicar a provável presença de patógenos, além de agentes deteriorantes. De maneira geral, alimentos com qualidade microbiológica satisfatória apresentam contagens de mesófilos aeróbios até $10^{4} \mathrm{UFC} / \mathrm{g}$ e ausência de patógenos (Perotto et al., 2021).

Em um estudo realizado por Souza et al. (2017), identificado como P20, foram feitas análises microbiológicas em polpas de cajá- umbu e cajá comercializados no município de Mossoró- RN. Para os resultados de bactérias mesófilas os autores encontraram valores como 2,93 x $10 \mathrm{UFC/g}$ nas polpas de cajá e 3,57 x 10 UFC/g nas polpas de cajá-umbu. Segundo os autores, a contagem de microrganismos aeróbios mesófilos não é considerada pela legislação, no entanto, altas contagens desses microrganismos indicam qualidade sanitária do alimento insatisfatória.

Santos et al. (2017), identificação P15, verificaram a qualidade microbiológica de polpas de frutas congeladas comercializadas no município Vitória da Conquista- BA. Foram analisadas polpas de acerola, manga e maracujá. Feita a análise de aeróbios mesófilos, os resultados foram valores que variam de 1 x $10^{1}$ e 4,1 x $10^{4}$. De acordo com os autores esses são valores considerados adequados para o consumo.

O Staphylococcus aureus é uma bactéria esférica, gram-positiva, que pode ser encontrada em pares, em pequenas cadeias ou em cachos similares aos de uva. A temperatura de multiplicação é entre 7 e $48{ }^{\circ} \mathrm{C}$, estes microrganismos podem ser encontrados no ar, na poeira, na água, no leite e nos alimentos ou equipamentos usados no processamento de alimentos. Os manipuladores de alimentos geralmente são as principais fontes de contaminação dos alimentos, quando há surtos, no entanto, os equipamentos e as superfícies também podem causar contaminações por Staphylococcus aureus (Forsythe, 2013).

Na pesquisa de Souza et al. (2016), identificação P19, analisou-se um total de 40 amostras de polpas de frutas, sendo essas de acerola, abacaxi, cajá, goiaba, graviola, mamão, manga e maracujá. Comercializadas em supermercados da cidade de Juazeiro do Norte - CE. Os resultados mostraram que 60\% das polpas de cajá, mamão e graviola tiveram contaminação por Staphylococcus aureus. De acordo com os autores a presença deste microrganismo pode estar associado as falhas durante o período de processamento do alimento como também condições higiênico-sanitárias deficientes dos equipamentos.

\section{Conclusão}

A avaliação do perfil microbiológico das polpas de frutas congeladas consumidas na região nordeste brasileiro demonstra que o setor enfrenta problemas acerca do processamento, controle de qualidade e padronização dos parâmetros microbiológicos preconizados pela legislação, apresentando produtos com altos índices de contaminação, classificados como impróprios para o consumo.

Falhas na execução correta das boas práticas de fabricação, deficiências na infraestrutura e a falta de fiscalização por parte dos órgãos responsáveis corroboram para um cenário de inconformidades, onde $65 \%$ dos estudos analisados apresentaram pelo menos uma amostra com valores em desacordo com os limites estabelecidos pela legislação, sendo o grupo de bolores e leveduras os microrganismos com maiores incidências de contaminação.

Em síntese, ações como capacitação periódica dos manipuladores, sanitização da matéria-prima, equipamentos e superfícies, aplicação de métodos de conservação combinados, aliadas a manutenção da cadeia do frio, constituem estratégias eficazes na conservação da qualidade microbiológica das polpas de frutas congeladas. 


\section{Referências}

Almeida, R. L. J., Santos, N. C., Queiroga, A. P. R., \& Luiz, M. R. (2018). Avaliação da qualidade microbiológica de polpas de morango (Fragaria vesca L.). Anais III CONAPESC.

Almico, J. D., Ferreira, I. M., Ramos, G. D., Silva, A. M. O., \& Carvalho, M. G. (2018). Avaliação da qualidade microbiológica, físico-química e química de polpas de açaí (Euterpe oleracea mart.) Pasteurizadas congeladas comercializadas em Aracaju-SE. Revista Brasileira de Higiene e Sanidade Animal, 12(2), 156-168.

Andrade, J. K. S., Ferreira, M. G. Q. L., Oliveira, E. H. S., Silva, E. A. S., Negreiros, H. A., Santos, G. M., barros, N, V. A., Cavalcante, R. M. S., Oliveira, J. M. S., Rios, M. J. B. L., Costa, C. M., Brito, M. M., \& Sousa, P. V. L. (2020). Qualidade microbiológica de polpas de açaí comercializadas em um estado do nordeste brasileiro. Brazilian Journal of Development, 6(3), 12215-12227.

Araújo, E. C. O. N., Alves, J. E. A., \& Marques, L. F. (2018). Avaliação de parâmetros de qualidade de polpas de frutas congeladas comercializadas no município de Salgueiro-PE. Revista Semiárido De Visu, 6(1), 4-11.

Brasil. Ministério da Agricultura, Pecuária e Abastecimento. Instrução Normativa $n^{o} 01$, de 07 de janeiro de 2000 . Regulamento técnico geral para fixação dos padrões de identidade e qualidade para polpa de fruta. Diário Oficial da República Federativa do Brasil, Brasília, DF, 10 jan. 2000.

Brasil. Ministério da Saúde. Resolução $n^{\circ} 12$, de 02 de janeiro de 2001. Regulamento técnico sobre padrões microbiológicos para alimentos. Diário Oficial da República Federativa do Brasil, Brasília, DF, 10 jan. 2001.

Brasil. Ministério da Agricultura, Pecuária e Abastecimento. Instrução Normativa $n^{\circ}$ 49, de 26 de setembro de 2018 . Instrução Normativa estabelece a complementação dos padrões de identidade e qualidade de suco e polpa de fruta. Diário Oficial da República Federativa do Brasil, Brasília, DF, 27, set. 2018.

Brasil. Ministério da Saúde. Resolução $n^{\circ}$ 60, de 23 de dezembro de 2019. Instrução Normativa estabelece as listas de padrões microbiológicos para alimentos prontos para oferta ao consumidor. Diário Oficial da República Federativa do Brasil, Brasília, DF, 26 dez. 2019.

Feitosa, R. C., Sousa, A. C. P., Teixeira, S. A., \& Medeiros, S. R. A. (2017). Avaliação da rotulagem da qualidade microbiológica e físico-química de polpas de frutas comercializadas em Picos-PI. Revista Intertox De Toxicologia, Risco Ambiental E Sociedade, v. 10, (n. 2), p. 62-72.

Ferreira, C. H. B., Espinheira, M. J. C. L., David, I. R., Duarte, S. F. P., Sousa, B. R., \& Souza, F. M. (2019). Quality acai marketed pulp microbiological in municipality of Victory Conquer BA. International Journal of Advanced Engineering Research and Science, 6(6), $712-719$.

Forsythe, S.J. Microbiologia da segurança dos alimentos. 2. ed. Porto Alegre: Artmed, 2013.

Franco, B.D.G.M.; Landgraf, M. Microbiologia dos alimentos. São Paulo: Atheneu, 2005.

Freitas, R. V. S., Souza, P. A., Soares, D. J., Reges, S. C. N., Oliveira, Z. L. de, \& Costa, F. B. da. (2020). Perfil da qualidade de polpas de frutas comercializadas no município de Limoeiro Do Norte, estado do Ceará, Brasil. Research, Society and Development, 9(8), e806986166.

Galvão, T. F., \& Pereira, M. G. (2014). Revisões sistemáticas da literatura: passos para sua elaboração. Epidemiologia e Serviços de Saúde, 183-184. https://doi.org/10.5123/S1679-49742014000100018.

Guimarães, T. L. F., Farias, V. L., Vidal, E. M. G., Oliveira, V. M. S., Souza, G. C., \& Moura, F. J. N. (2021). Qualidade microbiológica e microscópica de polpas de frutas congeladas comercializadas no município de Limoeiro Do Norte - CE. Research, Society and Development, 10(8). e23410817279e23410817279.

Marinho, O. S. C., Moura, A. R. N., Rabelo, H. P. S. M., Silva, G. M., \& Furtado, J. G, C. (2018). Condições microbiológicas de polpas congeladas de açaí comercializadas em mercados públicos de São Luís - MA. Journal of Health Connections, 2(1), 44-59.

Matta, V. M. d., Lourdes, M. F. J., Angela, M. C. C., \& Furtado, A. L. (2005). Polpa de fruta congelada (1a th ed.). Embrapa Informação Tecnológica.

Muniz, C. M., Reis, R. B. S., \& Vieira, V. F. (2017). Coliformes totais e Escherichia coli em polpas de frutas comercializadas no sudoeste da Bahia. ID on line Revista de Psicologia, 11(35), 180-187.

Neto, J. L. F., Calou, V. C. R., Silva, J. R. A., \& Mendes, R. C. (2016). Perfil microbiológico de amostras de polpas de frutas congeladas, comercializadas na cidade de Missão Velha - Ce. Caderno de Cultura e Ciência, 15(1), 47-56.

Oliveira, A. T. C. de, Silva, F. T. de S., Mendes, L. G., Monte, A. L. de S, \& Cavalcante, A. B. D. (2020). Perfil físico-químico e microbiológico de polpas de frutas congelada comercializadas em Limoeiro do Norte (CE). Research, Society and Development, $9(11)$, e549119473.

Oliveira, O. L. d., Almeida, A. P. F. d., Costa, F. R. d. S., Mendes, L. G., \& Cavalcante, A. B. D. (2020). Avaliação do padrão de identidade e qualidade de polpas de caju convencional (não pasteurizadas) e pasteurizada comercializadas no Estado do Ceará, Brasil. Research, Society and Development, v. 9(n. 9,)

Perotto, D. L., Vargas, B. K., Jacociunas, L. V., \& Wehmeyer, C. O. T. (2021). Microrganismos causadores de DTAs: um olhar pautado na legislação.

Santos, E. H. F., Figueiredo Neto, A., \& Donzeli, V. P. (2016). Aspectos físico-químicos e microbiológicos de polpas de frutas comercializadas em Petrolina (PE) e Juazeiro (BA). Brazilian Journal of Food Technology, 19, e2015089b.

Santos, V. M. S. Lima, G. S. Valencia, M. S. Salgado, M. S. Xavier, V. L. Qualidade físico-química, microbiológica e microscópica de polpas de frutas congeladas comercializadas na cidade de Recife, Pernambuco. Journal of Applied Pharmaceutical Sciences. (7): 26-41. 
Research, Society and Development, v. 10, n. 15, e105101522536, 2021 (CC BY 4.0) | ISSN 2525-3409 | DOI: http://dx.doi.org/10.33448/rsd-v10i15.22536

Santos, E. C. G., Santana, R. F., Júnior, N. M. V., \& Miranda, A. d. S. (2017). Determinação da qualidade microbiológica de polpa de frutas congeladas utilizando a técnica de filme de petri. Revista Brasileira de Produtos Agroindustriais. v.19. p.247-253.

Santos, R. E., \& Viera, P. P. F. (2020). Avaliação da qualidade microbiológica de polpas de frutas artesanais produzidas e comercializadas nos mercados públicos do município de João Pessoa. Brazilian Journal of Development, 6(9), 72847 -72857.

Santos, V. M., Lima, G. S., Valencia, M. S., \& Salgado, S. M. (2020). Qualidade físico-química, microbiológica e microscópica de polpas de frutas congeladas comercializadas na cidade de Recife, Pernambuco. Journal of Applied Pharmaceutical Sciences, 7, 26-41.

Sebastiany, E., Rego, E. R. D., \& Vital, M. J. S. (2009). Qualidade microbiológica de polpas de frutas congeladas. Revista do Instituto Adolfo Lutz (Impresso), 68(2), 224-231.

Silva, I. d. M. M. d., Freitas, F., Amor, A. L. M., Assunção, R. d. J., \& Silva, R. M. d. (2018.). Qualidade microbiológica de alimentos comercializados em Santo Antônio de Jesus - Bahia. Saúde, alimentos e meio ambiente no Recôncavo da Bahia, (Universidade Federal Do Recôncavo da Bahia - UFRB), 161p.

Silva, T. B. D. Martins, V. S. Pereira. J. M. C. Brasil, L. S. N. S. Silva, S.M.R. Análise microbiológica de polpas de frutas industrializadas comercializadas em supermercado em Belém do Pará. Revista Univap. São José dos Campos-SP. v. 26, n. 50, jul. 2020.

Silva, N., Junqueira, V. C. A., Silveira, N. F. De A., Taniwaki, M. H., Gomes, A.R., \& Okazaki, M. M. (2017). Manual de métodos de análise microbiológica de alimentos e água. 5. ed. São Paulo: Brucher.

Sousa, A. S., Soares, K. M.P., Góis, V. A., \& Freire, B. C. F. (2017). Qualidade microbiológica e físico-química de polpas de umbu-cajá e cajá comercializadas em Mossoró, RN. Higiene Alimentar, 31(272/273), 42-46.

Souza, J. C. C. O., Macedo, R. O., Leandro, L. M. G., Almeida, B. J., \& Fonseca, F. L. A. (2016). Avaliação microbiológica de polpas de frutas comercializadas na cidade de Juazeiro do Norte - CE. Higiene Alimentar, 30(254/255), 123-127.

Sousa, Y. A. Borges, M. A., Viana, A. F. d. S., Dias, A. L., Sousa, J. J. V. d., Silva, B. A. d., Silva, S. K. R. d., \& Aguiar, F. S. d. (2020). Avaliação físicoquímica e microbiológica de polpas de frutas congeladas comercializadas em Santarém - PA. Brazilian Journal of Food Technology, v. 23.

Torres, L. C. P., Moura, R. d. C., Aguiar, R. O., Santos, D. B. d., Santos, M. A. S. d., Martins, L. H. d. S., Silva, P. A., \& Bernardino, P. D. L. d. S., (2020). Avaliação da qualidade de polpas de frutas congeladas comercializadas na Região de Carajás - PA. Research, Society and Development, 9(10).

Vidal, M. F. (2020). Fruticultura na área de atuação do BNB: produção, mercado e perspectivas. Caderno Setorial ETENE. s1dspp01.dmz.bnb:8443/s482dspace/handle/123456789/390.

Zucoloto, M., Schmildt, E. D., \& Coelho, R. I. (2015). Fruticultura tropical: diversificação e consolidação. CAUFES. https://biblioteca.incaper.es.gov.br/digital/bitstream/123456789/3174/1/BRT-fruticulturatropical-v.1.pdf 